\title{
A novel functional polymorphism (-336A/G) in the promoter of the partitioning-defective protein-6 $\alpha$ gene is associated with increased glucose tolerance and lower concentrations of serum non-esterified fatty acids
}

Received: 3 September 2004 / Accepted: 17 November 2004 / Published online: 3 March 2005

(C) Springer-Verlag 2005

\begin{abstract}
Aims/hypothesis: Partitioning-defective protein$6 \alpha(\operatorname{Par} 6 \alpha)$ has recently been demonstrated to negatively regulate insulin signalling in murine myoblasts. To address whether Par6 $\alpha$ plays a role in human physiology, the present study investigated whether mutations exist in the Par6 $\alpha$ gene and whether these mutations, if present, are associated with pre-diabetic phenotypes in non-diabetic subjects. Methods: The complete gene (part of the promoter [2.1 kb], all exons/introns and the $3^{\prime}$ untranslated region) encoding Par6 $\alpha$ was analysed in 664 non-diabetic subjects. We investigated possible associations between single nucleotide polymorphisms and percentage of body fat, glucose tolerance (as determined by OGTT), serum NEFA concentrations and whole-body insulin sensitivity (estimated during the OGTT, and for a subgroup of 242 subjects determined by the euglycaemic-hyperinsulinaemic clamp). Results: A rare $A / G$ polymorphism was found 336-bp upstream of the translational start codon (allele frequency 0.03 ). The data for subjects homozygous and heterozygous for $-336 G(R / G, n=43)$ were combined and compared with those for subjects homozygous for $-336 \mathrm{~A}$ $(A / A, n=621)$. Subjects with the $R / G$ genotype had lower fasting ( $4.84 \pm 0.09 \mathrm{mmol} / \mathrm{l}$, means $\pm \mathrm{SEM}, p=0.049)$ and 2 -h $(5.50 \pm 0.02 \mathrm{mmol} / \mathrm{l}, p=0.050)$ plasma glucose concentrations than subjects with the $A / A$ genotype $(5.02 \pm 0.02$ and $5.94 \pm 0.06 \mathrm{mmol} / \mathrm{l}$, respectively). Subjects with the $R / G$ genotype also had lower fasting $(448 \pm 31 \mu \mathrm{mol} / 1, p=0.018)$ and 2-h serum NEFA concentrations $(61 \pm 7 \mu \mathrm{mol} / \mathrm{l}, p=$ 0.015 ) than subjects with the $A / A$ genotype (529 \pm 9 and $75 \pm$ $2 \mu \mathrm{mol} / 1$, respectively), adjusted for age, sex and percentage of body fat. There were no differences in adiposity or
\end{abstract}

P. Weyrich · R. Lammers · A. Fritsche $\cdot$ F. Machicao ·

H.-U. Häring · N. Stefan $(\bowtie)$

Department of Internal Medicine, Division of Endocrinology, Metabolism and Pathobiochemistry, University of Tübingen,

Otfried-Müller-Str.10,

72076 Tübingen, Germany

e-mail: norbert.stefan@med.uni-tuebingen.de

Tel.: +49-7071-2980390

Fax: +49-7071-295974 whole-body insulin sensitivity between the two genotype groups (all $p>0.36$ ). A luciferase reporter gene assay revealed that the $-336 \mathrm{G}$ promoter variant had a significantly lower $(-22.8 \%, p=0.006)$ transcriptional activity in transfected $\mathrm{C} 2 \mathrm{C} 12$ murine myoblasts than the $-336 \mathrm{~A}$ promoter variant. Conclusions/interpretation: A novel functional variant in the promoter of the Par $6 \alpha$ gene is associated with reduced fasting glycaemia, increased glucose tolerance and reduced serum NEFA concentrations.

Keywords Atypical protein kinase $\mathrm{C} \cdot \mathrm{C} 2 \mathrm{C} 12$ cells . Glucose tolerance $\cdot$ NEFA - OGTT · Par6 protein ·

Reporter gene assay

Abbreviations aPKCs: atypical isoforms of protein kinase C - IRS-1: insulin receptor substrate-1 - Par6: partitioning-defective protein- 6 - PI3K:

phosphatidylinositol-3-kinase $\cdot \operatorname{PPAR} \gamma 2$ : peroxisome proliferator-activated receptor- $\gamma 2$ - SNP: single

nucleotide polymorphism

\section{Introduction}

The pathogenesis of type 2 diabetes involves a combined defect in insulin secretion and insulin action [1]. The atypical isoforms of protein kinase $\mathrm{C}$ (aPKCs) play important roles in the modulation of insulin action. These serine/ threonine kinases have been shown to be positively involved in the transport of glucose in fat and muscle in various cell lines and animal models [2]. However, aPKCs also exert a negative regulatory function on insulin action. Firstly, aPKCs are able to phosphorylate insulin receptor substrate-1 (IRS-1) on serine residues, thereby downregulating the recruitment and activation of phosphatidylinositol-3-kinase (PI3K) by IRS-1, especially under prolonged stimulation with insulin [3-5]. Secondly, when stimulated with ceramide, aPKCs directly inhibit protein kinase $\mathrm{B}(\alpha)$ [6], one of the key molecules required for insulin-dependent glucose transport and glycogen synthesis [7,8]. 
Both aPKC-dependent inhibitory mechanisms may be involved in the pathogenesis of type 2 diabetes. Thus, it is important to understand how aPKCs are regulated in insulin signalling.

Several aPKC-interacting proteins influence aPKC activity and substrate specificity [9], including the partitioning-defective protein-6 (Par6) family, which comprises three isoforms $(\alpha, \beta$ and $\gamma)$. Par6 activates the aPKCs via an unknown mechanism and plays an important role in asymmetric cell division and cell polarisation $[10,11]$. Par6 has also been shown to play a role in insulin signalling in 3T3L1 adipocytes [12]. We have recently demonstrated that the $\alpha$ isoform of Par6 (Par6 $\alpha$ ) is expressed in human insulinsensitive tissues (liver, brain, muscle, pancreas) and that overexpressed Par6 $\alpha$ enhances the negative effect of the aPKCs on insulin action in C2C12 murine myoblasts [13]. However, little is known about the effects of Par6 $\alpha$ on insulin sensitivity in humans. In the present study we therefore investigated whether mutations exist in the human gene encoding Par6 $\alpha$ and whether these mutations, if present, are associated with pre-diabetic phenotypes in a nondiabetic population.

\section{Subjects and methods}

Subjects We analysed data on 664 subjects with normal or impaired glucose tolerance [14] who participated in the Tübingen Family Study of type 2 diabetes. The participants were not receiving any medication known to affect glucose tolerance or insulin sensitivity. Of the total study population, 242 underwent a euglycaemic-hyperinsulinaemic clamp. Tests were performed at $0800 \mathrm{~h}$ after an overnight fast of $10 \mathrm{~h}$. Subjects were asked to refrain from smoking over the same period. Informed written consent was obtained from all participants and the protocol was approved by the local medical ethics committee. The characteristics of the subjects are shown in Table 1.

Body composition and body fat distribution Body composition was measured by bioelectrical impedance as percentage of body fat. BMI was calculated as weight divided by the square of height $\left(\mathrm{kg} / \mathrm{m}^{2}\right)$. Waist and hip circumferences were measured with subjects in the supine position, and the WHR was calculated as an index of the distribution of body fat.

Oral glucose tolerance test All subjects underwent an OGTT [15]. After an overnight fast, subjects ingested a solution containing $75 \mathrm{~g}$ of dextrose, and venous blood samples were obtained at $0,30,60,90$ and $120 \mathrm{~min}$ for determination of plasma glucose concentrations. Insulin sensitivity was calculated from the glucose and insulin concentrations measured during the OGTT using the formula proposed by Matsuda and DeFronzo [16]. Serum NEFA concentrations were measured at 0 and $120 \mathrm{~min}$.

Whole-body insulin sensitivity At approximately $0800 \mathrm{~h}$, an antecubital vein was cannulated for infusion of insulin
Table 1 Characteristics of the subjects divided according to genotype of the $-336 A / G$ polymorphism in the Par6 $\alpha$ gene

\begin{tabular}{|c|c|c|c|}
\hline & \multicolumn{3}{|c|}{ Genotype $(n=664)$} \\
\hline & $A / A$ & $\mathrm{R} / \mathrm{G}$ & $p$ Value \\
\hline Sex (male/female) & $218 / 403$ & $13 / 30$ & $0.51^{\mathrm{a}}$ \\
\hline Age (years) & $37 \pm 1$ & $35 \pm 1$ & 0.24 \\
\hline WHR & $0.86 \pm 0.01$ & $0.84 \pm 0.01$ & 0.27 \\
\hline BMI $\left(\mathrm{kg} / \mathrm{m}^{2}\right)$ & $26.5 \pm 0.2$ & $27.2 \pm 1.1$ & 0.53 \\
\hline Body fat (\%) & $28.4 \pm 0.4$ & $29.0 \pm 0.03$ & 0.98 \\
\hline $\begin{array}{l}\text { Fasting plasma } \\
\text { insulin }(\mathrm{pmol} / \mathrm{l})\end{array}$ & $5.44 \pm 0.06$ & $5.54 \pm 0.06$ & 0.96 \\
\hline $\begin{array}{l}\text { 2-h plasma insulin } \\
(\mathrm{pmol} / \mathrm{l})\end{array}$ & $49 \pm 2$ & $51 \pm 2$ & 0.17 \\
\hline $\begin{array}{l}\text { Insulin sensitivity } \\
\text { (agTT) } \\
\text { (arbitrary units) }\end{array}$ & $18.8 \pm 0.5$ & $21.1 \pm 2.0$ & 0.37 \\
\hline $\begin{array}{l}\text { Insulin sensitivity }_{(\text {clamp) }} \\
\left(\mu \mathrm{mol} \cdot \mathrm{kg}^{-1} \cdot \min ^{-1} \cdot[\mathrm{pmol} / 1]^{-1}\right)^{\mathrm{b}}\end{array}$ & $0.102 \pm 0.004$ & $0.098 \pm 0.014$ & 0.99 \\
\hline
\end{tabular}

The data are means \pm SEM. The $p$ values were calculated using general linear models. Anthropometric measurements were adjusted for age and sex; insulinaemia and insulin sensitivity were also adjusted for percentage of body fat

${ }^{a}$ According to the Chi square test

$\mathrm{b}_{n=242}$

and glucose. A dorsal hand vein of the contralateral arm was cannulated and placed under a heating device to permit sampling of arterialised blood. After basal blood was drawn, subjects received a primed insulin infusion at a 27 rate of 1.0 $\mathrm{mU} \cdot \mathrm{kg}^{-1} \cdot \mathrm{min}^{-1}$ for $2 \mathrm{~h}$. Blood was drawn every $5 \mathrm{~min}$ for the determination of blood glucose, and a glucose infusion was adjusted such that fasting glucose levels were maintained. An insulin sensitivity index (in $\mu \mathrm{mol} \cdot \mathrm{kg}^{-1} \cdot \mathrm{min}^{-1}$. $\left.[\mathrm{pmol} / 1]^{-1}\right)$ for systemic glucose uptake was calculated as the mean infusion rate of glucose (in $\mu \mathrm{mol} \cdot \mathrm{kg}^{-1} \cdot \mathrm{min}^{-1}$ ) necessary to maintain euglycaemia during the last $60 \mathrm{~min}$ of the euglycaemic-hyperinsulinaemic clamp divided by the steady-state serum insulin concentration.

Analytical procedures Blood glucose was determined by the glucose oxidase method using a bedside glucose analyser (YSI Blood Glucose Analyzer; Yellow Springs Instruments, Yellow Springs, CO, USA). Plasma insulin was determined by microparticle enzyme immunoassay (Abbott Laboratories, Tokyo, Japan). Serum NEFA concentrations were determined using an enzymatic method (WAKO Chemicals, Neuss, Germany).

Genotyping Genomic DNA was isolated from whole blood using a commercial DNA isolation kit (NucleoSpin; Macherey-Nagel, Düren, Germany). Oligonucleotide primers were designed in order to amplify the gene encoding Par6 $\alpha$. Use of these primers revealed amplification products of approximately $400 \mathrm{bp}$. By 14 overlapping reactions, the complete gene (part of the promoter [2.1 kb], all exons/introns and the $3^{\prime}$ untranslated region) was amplified by PCR in a screen of 50 subjects (Fig. 1). The PCR products were then sequenced bidirectionally using an ABI Prism dye terminator cycle sequencing ready reaction 


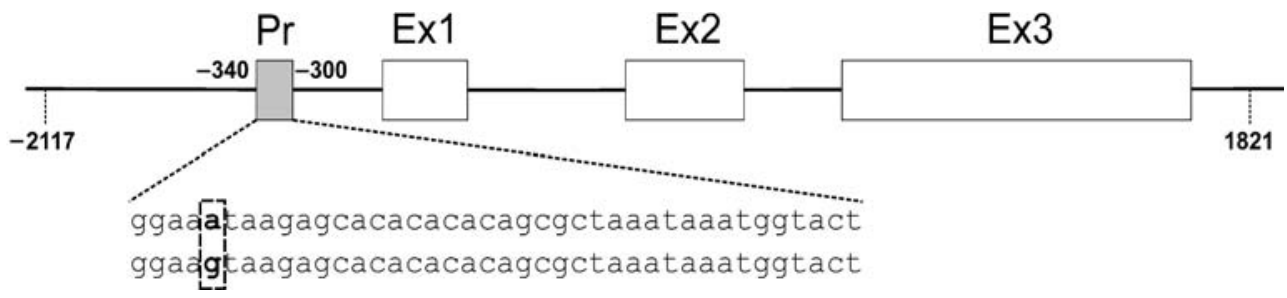

Fig. 1 Structure of the Par $6 \alpha$ gene. The gene encoding Par6 $\alpha$ is located on chromosome 16q22 and comprises three exons (ExI-Ex3, white boxes). The outer nucleotide numbers ( -2117 and 1821) indicate the genomic region analysed for this work. The GenScan algo-

kit (Applied Biosystems, Foster City, CA, USA) and an ABI Prism 310 automated sequencer (Applied Biosystems). Genotyping of the newly detected single nucleotide polymorphism (SNP) was achieved using the TaqMan assay (Applied Biosystems). The TaqMan genotyping reaction was amplified using a GeneAmp PCR system 7000 $\left(95^{\circ} \mathrm{C}\right.$ for $10 \mathrm{~min}$, then 38 cycles at $95^{\circ} \mathrm{C}$ for $15 \mathrm{~s}, 62^{\circ} \mathrm{C}$ for $1 \mathrm{~min}$ ), and fluorescence was detected using an ABI Prism 7000 sequence detector (Applied Biosystems). As a quality standard, we randomly included six positive $(2 \times A / A$, $2 \times A / G, 2 \times G / G)$ and two negative (all components excluding DNA) sequenced controls in each TaqMan reader plate. Because all controls were correctly identified, we assumed that the genotyping error rate of this method did not exceed $0.3 \%$, as demonstrated previously in a study designed to validate this method [17].

Reporter gene assay A promoter region of the human Par6 $\alpha$ gene comprising nucleotides -1253 to +109 (position relative to the translational start codon) was amplified from the genomic DNA of a heterozygous $-336 A / G$ subject using the forward primer 5'-CTTCTCCTCCCTGCAACA AG-3' and the reverse primer 5'-AAGAGGGAATTGGGA GCG-3'. The fragment was subcloned into the pCR-Blunt vector (Invitrogen, Carlsbad, CA, USA). Clones containing the $-336 \mathrm{~A}$ or the $-336 \mathrm{G}$ variant of the promoter were identified by sequencing. Both promoter fragments were obtained by restriction with EcoRI (New England Biolabs, Beverly, MA, USA), were blunted with a Klenow fill-in and were inserted into pGL3(R2.1) Basic Vector (Promega, Madison, WI, USA) containing the firefly luciferase reporter gene, which was cleaved using SmaI. After confirmation of correct orientation, pGL3(R2.1) Basic Vectors containing the Par $6 \alpha$ gene promoter variants and a positive control vector containing the Renilla reniformis luciferase under the control of the Herpes simplex virus thymidine kinase (pRL-TK; Promega) were cotransfected at a ratio of $3: 1$ into C2C12 cells cultured with DMEM $+10 \%$ FCS +2 $\mathrm{mmol} / \mathrm{l}$ glutamine. After $48 \mathrm{~h}$, cells were washed with PBS and extracted into the lysis buffer provided with the Dual Luciferase Reporter Assay System (Promega). Firefly luciferase activity was measured according to the manufacturer's protocol with a Magic Lite Analyzer (Ciba Corning, Essex, UK) and was normalised to the corresponding Renilla luciferase activity. Each transfection was performed 16 times. rithm [18] predicted a promoter element ( $P r$, shaded box) at -340 - to -300 -bp upstream of the translational start codon. The sequence of this promoter region, including the $-336 \mathrm{~A} / \mathrm{G} \mathrm{SNP}$, is displayed in the bottom panel.

Statistical analyses Unless stated otherwise, data are provided as means \pm SEM. Statistical comparison of genotype groups was performed using logarithmically transformed data (for non-normally distributed parameters). Multivariate linear regression analyses were performed to adjust for the effects of relevant covariates (age, sex, percentage of body fat). A $p$ value less than or equal to 0.05 was considered to be statistically significant. The analyses were conducted using the JMP statistical software package (SAS

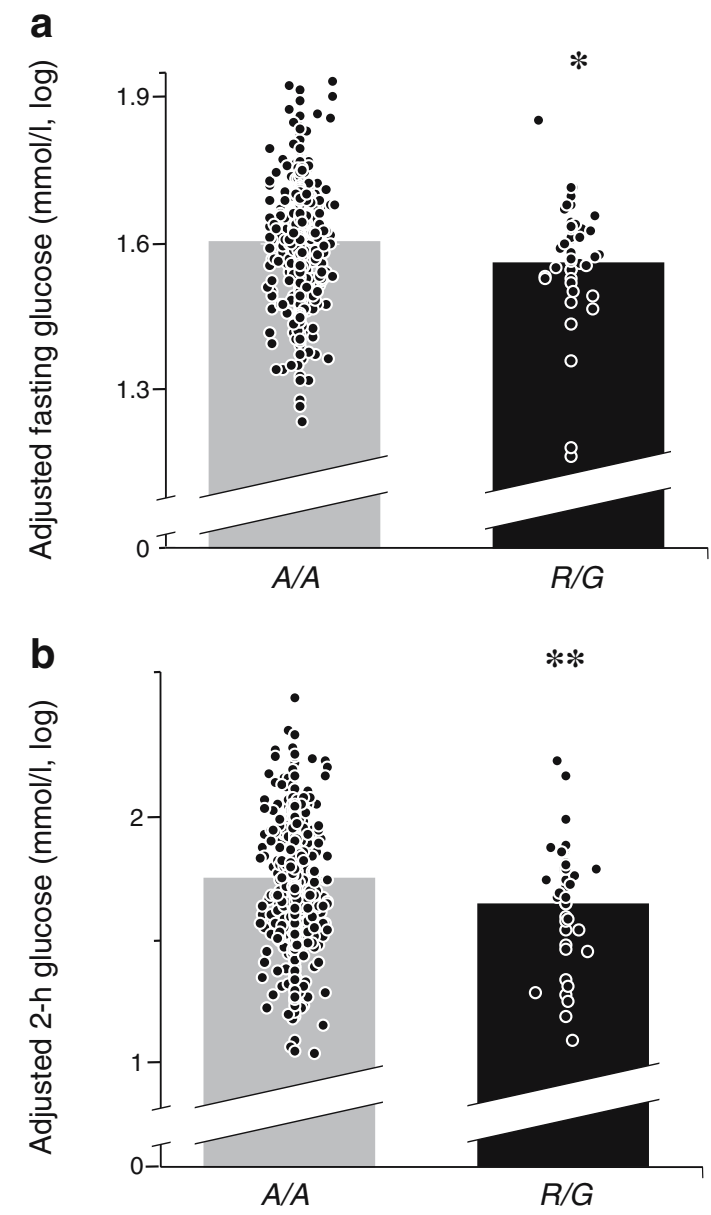

Fig. 2 Associations between the genotypes of the $-336 \mathrm{~A} / \mathrm{G}$ polymorphism in the Par6 $\alpha$ gene and fasting (a) and 2-h (b) glycaemia during an OGTT. $* p=0.049$ and $* * p=0.050$ vs $A / A$ genotype after adjustment for age, sex and percentage of body fat 
Institute, Cary, NC, USA) or SPSS software (SPSS, Chicago, IL, USA).

\section{Results}

We screened 50 subjects who participated in the Tübingen Family Study of type 2 diabetes. Previously reported SNPs in the Par $6 \alpha$ gene (three in the promoter region, one in exon 1 , three in the $3^{\prime}$ untranslated region), which are listed in the dbSNP database (http://www.ncbi.nlm.nih.gov/SNP, last accessed in January 2005), were not detected in our population. However, a novel SNP $(A / G)$ was detected 336-bp upstream of the translational start codon. Interestingly, using the GenScan software [18], we found that the SNP was located within a 40 -bp region $(-340$ to -300$)$ predicted to function as a promoter for the Par6 $\alpha$ gene (Fig. 1). The allelic frequency of this rare SNP was 0.03 in our population. Genotype frequencies were in Hardy-Weinberg equilibrium ( $p=0.34$ according to the Chi square test). For
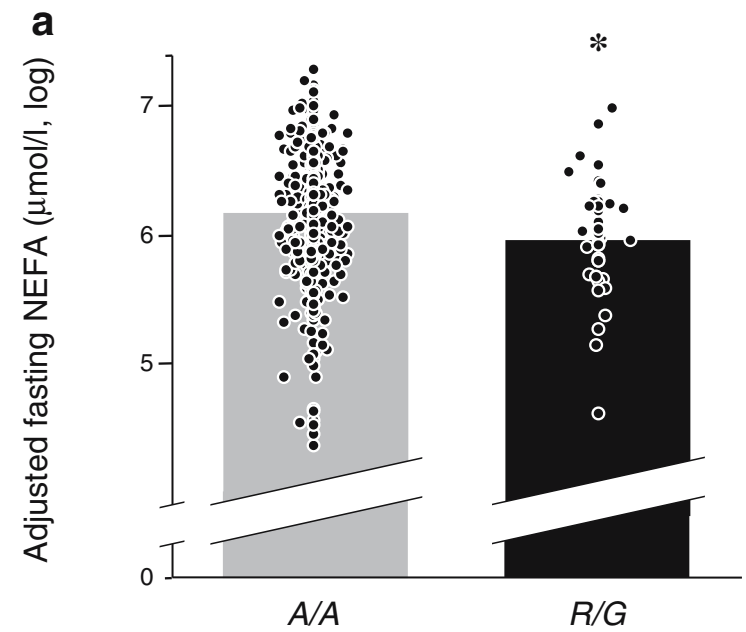

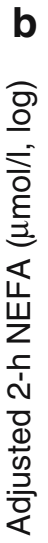

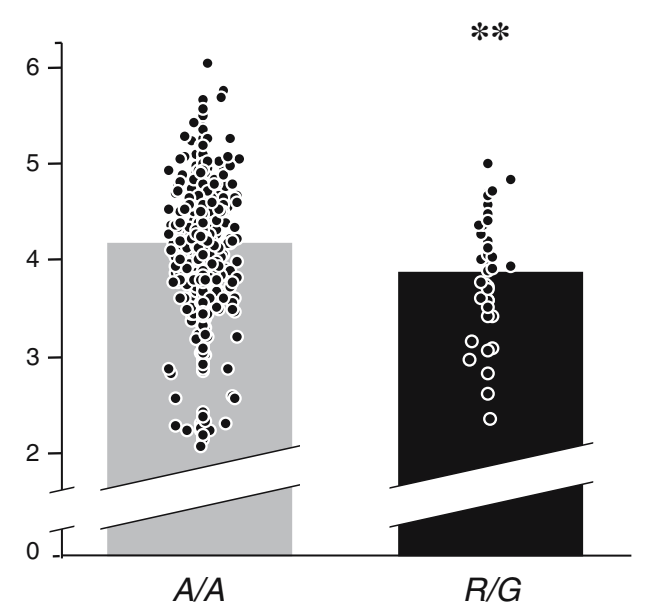

Fig. 3 Associations between the genotypes of the $-336 A / G$ polymorphism in the Par6 $\alpha$ gene with fasting (a) and 2-h (b) serum NEFA concentrations during an OGTT. * $p=0.018$ and $* * p=0.015$ vs $A / A$ genotype after adjustment for age, sex and percentage body fat statistical analysis, the results for subjects homozygous $(n=2)$ and heterozygous $(n=41)$ for the $-336 G$ allele were combined $(R / G, n=43)$ and compared with those of subjects homozygous for the $-336 A$ allele $(A / A, n=621)$ (Table 1). There were no differences between the two groups with respect to age, sex, body fat distribution or adiposity. However, subjects with the $R / G$ genotype had lower fasting (4.84 $\pm 0.09 \mathrm{mmol} / \mathrm{l}, p=0.049)$ and 2 -h $(5.50 \pm 0.02 \mathrm{mmol} / \mathrm{l}$, $p=0.050)$ plasma glucose concentrations compared with subjects with the $A / A$ genotype (5.02 \pm 0.02 and $5.94 \pm 0.06$ $\mathrm{mmol} / \mathrm{l}$, respectively) (Fig. 2). Subjects with the $R / G$ genotype also had lower fasting $(448 \pm 31 \mu \mathrm{mol} / 1, p=0.018)$ and 2-h $(61 \pm 7 \mu \mathrm{mol} / \mathrm{l}, p=0.015)$ serum NEFA concentrations compared with subjects with the $A / A$ genotype (529 \pm 9 and $75 \pm 2 \mu \mathrm{mol} / 1$, respectively) (Fig. 3), after adjustment for age, sex and percentage of body fat. There were no differences between the two groups in terms of insulinaemia or whole-body insulin sensitivity as determined during the OGTT and/or the euglycaemic-hyperinsulinaemic clamp (both $p>0.36$; Table 1). Furthermore, genotype was not associated with serum triglycerides or total, HDL or LDL cholesterol levels ( $n=644$, all $p>0.29$; data not shown).

The Pro12Ala polymorphism of the peroxisome proliferator-activated receptor- $\gamma 2$ gene (PPAR $\gamma 2)$ is a genetic variant that influences the sensitivity of lipolysis to insulin [19]. We investigated whether the effects of the $-336 A / G$ polymorphism in the Par6 $\alpha$ gene on serum NEFA concentrations were similar to those observed for the Pro12Ala variant by comparing serum NEFA concentrations in a subgroup of the study population that was genotyped for both genetic variants $(n=629$; data not shown). The Pro12Ala polymorphism was associated with $9 \%$ lower fasting serum NEFA concentrations and 12\% lower 2-h serum NEFA concentrations. These effects were comparable to those observed for the $-336 A / G$ polymorphism of the Par6 $\alpha$ gene in this subgroup (13 and $11 \%$, respectively). We also found that the effects of the $-336 \mathrm{~A} / \mathrm{G}$ polymorphism on serum NEFA concentrations (basal and $2 \mathrm{~h})$ were independent of the Pro12Ala variant of the PPAR $\gamma 2$ gene (both $p=0.057$ according to general linear

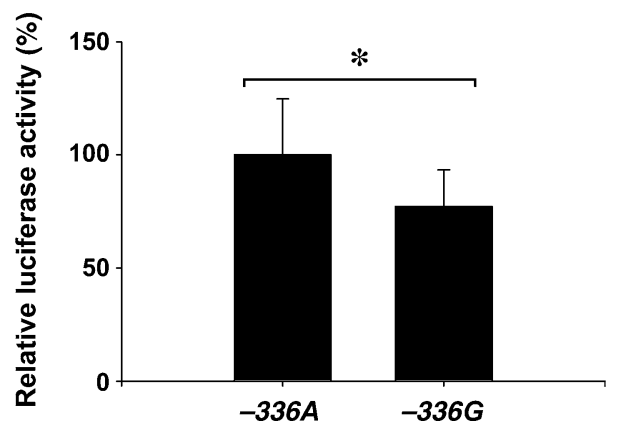

Fig. 4 Comparison of promoter activity with either $A$ or $G$ at position -336 . Promoter activity was assayed with the dual luciferase assay in transiently transfected $\mathrm{C} 2 \mathrm{C} 12$ murine myoblasts. The mean ratio of firefly:Renilla luciferase activity of the wild-type promoter construct $(-336 A)$ is shown as $100 \%$ relative activity. Data were obtained from 16 independent experiments and are expressed as means + SEM. ${ }^{*} p=0.006$ using an unpaired Student's $t$-test 
models, after adjustment for the variability in the Pro12Ala polymorphism).

To investigate whether the newly detected SNP in the promoter of the Par6 $\alpha$ gene influences the transcription of the gene, we tested both promoter variants in a reporter gene assay. After normalisation of luciferase activities to the corresponding transfection efficiencies, a significantly lower $(-22.8 \%, p=0.006)$ transcriptional rate was observed in $\mathrm{C} 2 \mathrm{C} 12$ cells expressing the $-336 \mathrm{G}$ promoter construct compared with cells expressing the wild-type promoter of the Par6 $\alpha$ gene ( $n=16$; Fig. 4 ).

\section{Discussion}

This is the first report on the associations between genetic variations in the Par $6 \alpha$ gene and pre-diabetic phenotypes. The results presented in this paper strengthen the hypothesis that Par6 $\alpha$ may play a role in glucose and lipid metabolism in humans. Due to the observed associations between the polymorphism and fasting glucose and glucose tolerance, we expected the SNP to have an effect on whole-body insulin sensitivity as determined during the OGTT and the euglycaemic-hyperinsulinaemic clamp. However, whole-body insulin sensitivity was not found to be different between genotypes. At first glance, this finding implies that the SNP in the promoter of the Par6 $\alpha$ gene may not be important in liver and muscle, the main tissues influencing whole-body insulin sensitivity. Nevertheless, it may be speculated that Par6 $\alpha$ specifically plays a role in liver. The results of a previous study suggest that basal and 2-h glycaemia are largely influenced by basal and insulinsuppressed hepatic glucose production, both of which are measurements of hepatic insulin sensitivity [20]. However, it has also been shown that IGT primarily results from the reduced suppression of hepatic glucose output due to abnormal pancreatic islet function [21]. In the present study, hepatic insulin sensitivity was not directly determined; hence, further investigations are warranted to clarify this issue.

In addition to the association with glycaemia, we found that the polymorphism affected fasting and 2-h NEFA concentrations. Both basal and post-load NEFA concentrations are indirect measurements of the insulin sensitivity of lipolysis. Thus, it can be speculated that these results indicate a role for $\operatorname{Par} 6 \alpha$ in the regulation of lipolysis. It appears possible that the decreased release of NEFAs would permit the liver to suppress glucose production more efficiently under basal and insulin-stimulated conditions. To date, high levels of expression of human Par6 $\alpha$ have only been verified in adult insulin-sensitive tissues, such as brain, liver, pancreas and skeletal muscle [22-24]. We have also recently demonstrated Par6 $\alpha$ expression in the visceral adipose tissue of C57B16 mice (unpublished observation). This finding further supports a role for Par6 $\alpha$ in adipose tissue lipid metabolism. Our subgroup analysis of subjects genotyped for both the Pro12Ala and $-336 A / G$ polymorphisms revealed that the SNP in the Par6 $\alpha$ gene was associated with reductions in fasting and 2-h NEFA con- centrations that were similar to those observed for the Pro12Ala variant; this effect still tended to be significant after adjustment for the latter. Thus, although the SNP in the Par6 $\alpha$ gene has a much lower allelic frequency than the Pro12Ala variant, it has a similar effect on serum NEFA concentrations. Nevertheless, the $-336 A / G$ polymorphism probably does not account for a large part of the variability in fasting and 2-h glucose concentrations observed in this study. Whether it is more important in other populations needs to be determined.

The SNP described in this paper is located in a 40-bp region that was predicted to represent the promoter for the Par6 $\alpha$ gene by the GenScan software, which provides a reliable algorithm for the identification of promoter elements and genes [18]. Analysis of this promoter sequence using the TRANSFAC database (http://www.gene-regulation.com/ pub/databases.html\#transfac, last accessed in January 2005) [25] revealed that it contains a protein-binding motif (GG AAAT) previously detected in the promoter of the human insulin gene by a DNAse-footprinting assay [26]. This GG AAAT motif is changed to GGAAGT by the $-336 A / G$ SNP. It may therefore be surmised that the SNP influences the binding affinity of an as yet unknown transcription factor that possibly regulates the transcription of the Par $6 \alpha$ gene. Interestingly, the data we obtained from the reporter gene assay in $\mathrm{C} 2 \mathrm{C} 12$ cells confirmed that the $-336 G$ promoter variant resulted in a significantly lower transcriptional activity compared with the $-336 \mathrm{~A}$ variant. The finding that Par6 $\alpha$ negatively regulates insulin signalling in $\mathrm{C} 2 \mathrm{C} 12$ cells [13] supports the hypothesis that the decreased expression of Par6 $\alpha$ may account for the effects observed in SNP carriers.

In conclusion, this is the first report to show that a functional variant in the promoter of the Par $6 \alpha$ gene is correlated with glycaemia and serum NEFA concentrations in humans. These data support our hypothesis that the Par6 $\alpha$ gene represents a candidate gene for type 2 diabetes.

Acknowledgements We thank all the research volunteers for their participation. We gratefully acknowledge the superb technical assistance of M. Melzer, D. Neuscheler, E. Maerker, A. Teigeler and H. Luz. The authors would like to thank all participants for their cooperation. The studies were in part supported by grants from the Deutsche Forschungsgemeinschaft (KFO 114/1) and the European Union (QLRT-1999-00674).

\section{References}

1. Gerich JE (1998) The genetic basis of type 2 diabetes mellitus: impaired insulin secretion versus impaired insulin sensitivity. Endocr Rev 19:491-503

2. Farese RV (2002) Function and dysfunction of aPKC isoforms for glucose transport in insulin-sensitive and insulin-resistant states. Am J Physiol Endocrinol Metab 283:E1-E11

3. Moeschel K, Beck A, Weigert C et al (2004) Protein kinase Czeta-induced phosphorylation of Ser318 in insulin receptor substrate-1 (IRS-1) attenuates the interaction with the insulin receptor and the tyrosine phosphorylation of IRS-1. J Biol Chem 279:25157-25163 
4. Liu YF, Paz K, Herschkovitz A et al (2001) Insulin stimulates PKCzeta-mediated phosphorylation of insulin receptor substrate-1 (IRS-1). A self-attenuated mechanism to negatively regulate the function of IRS proteins. J Biol Chem 276:1445914465

5. Ravichandran LV, Esposito DL, Chen J, Quon MJ (2001) Protein kinase C-zeta phosphorylates insulin receptor substrate-1 and impairs its ability to activate phosphatidylinositol 3-kinase in response to insulin. J Biol Chem 276:3543-3549

6. Powell DJ, Hajduch E, Kular G, Hundal HS (2003) Ceramide disables 3-phosphoinositide binding to the pleckstrin homology domain of protein kinase B (PKB)/Akt by a PKCzeta-dependent mechanism. Mol Cell Biol 23:7794-7808

7. Whiteman EL, Cho H, Birnbaum MJ (2002) Role of Akt/ protein kinase B in metabolism. Trends Endocrinol Metab 13: 444-451

8. Hajduch E, Litherland GJ, Hundal HS (2001) Protein kinase B (PKB/Akt) - a key regulator of glucose transport? FEBS Lett 492:199-203

9. Moscat J, Diaz-Meco MT (2000) The atypical protein kinase Cs. Functional specificity mediated by specific protein adapters. EMBO Rep 1:399-403

10. Wodarz A (2002) Establishing cell polarity in development. Nat Cell Biol 4:E39-E44

11. Etienne-Manneville S, Hall A (2003) Cell polarity: Par6, aPKC and cytoskeletal crosstalk. Curr Opin Cell Biol 15:67-72

12. Kanzaki M, Mora S, Hwang JB, Saltiel AR, Pessin JE (2004) Atypical protein kinase $\mathrm{C}(\mathrm{PKC} \zeta / \lambda)$ is a convergent downstream target of the insulin-stimulated phosphatidylinositol 3kinase and TC10 signaling pathways. J Cell Biol 164:279-290

13. Weyrich P, Kapp K, Niederfellner G et al (2004) Partitioningdefective protein 6 regulates insulin-dependent glycogen synthesis via atypical protein kinase C. Mol Endocrinol 18:1287-1300

14. Thamer C, Stumvoll M, Niess A et al (2003) Reduced skeletal muscle oxygen uptake and reduced beta-cell function: two early abnormalities in normal glucose-tolerant offspring of patients with type 2 diabetes. Diabetes Care 26:2126-2132

15. World Health Organization Expert Committee on Diabetes Mellitus (1980) World health organization expert committee on diabetes mellitus: second report. World Health Organ Tech Rep Ser 646:1-80
16. Matsuda M, DeFronzo RA (1999) Insulin sensitivity indices obtained from oral glucose tolerance testing: comparison with the euglycemic insulin clamp. Diabetes Care 22:1462-1470

17. Olivier M, Chuang LM, Chang MS et al (2002) High-throughput genotyping of single nucleotide polymorphisms using new biplex invader technology. Nucleic Acids Res 30:e53

18. Burge C, Karlin S (1997) Prediction of complete gene structures in human genomic DNA. J Mol Biol 268:78-94

19. Stumvoll M, Wahl HG, Loblein K et al (2001) Pro12Ala polymorphism in the peroxisome proliferator-activated receptor-gamma2 gene is associated with increased antilipolytic insulin sensitivity. Diabetes 50:876-881

20. Bavenholm PN, Pigon J, Ostenson CG, Efendic S (2001) Insulin sensitivity of suppression of endogenous glucose production is the single most important determinant of glucose tolerance. Diabetes 50:1449-1454

21. Mitrakou A, Kelley D, Mokan M et al (1992) Role of reduced suppression of glucose production and diminished early insulin release in impaired glucose tolerance. N Engl J Med 326:22-29

22. Joberty G, Petersen C, Gao L, Macara IG (2000) The cell-polarity protein Par6 links Par3 and atypical protein kinase $\mathrm{C}$ to Cdc42. Nat Cell Biol 2:531-539

23. Noda Y, Takeya R, Ohno S, Naito S, Ito T, Sumimoto H (2001) Human homologues of the Caenorhabditis elegans cell polarity protein PAR6 as an adaptor that links the small GTPases Rac and Cdc42 to atypical protein kinase C. Genes Cells 6:107-119

24. Qiu RG, Abo A, Steven Martin G (2000) A human homolog of the C. elegans polarity determinant Par-6 links Rac and Cdc42 to PKCzeta signaling and cell transformation. Curr Biol 10: 697-707

25. Matys V, Fricke E, Geffers R et al (2003) TRANSFAC: transcriptional regulation, from patterns to profiles. Nucleic Acids Res 31:374-378

26. Boam DS, Clark AR, Docherty K (1990) Positive and negative regulation of the human insulin gene by multiple trans-acting factors. J Biol Chem 265:8285-8296 